\title{
Article \\ Mathematical Tool Based on Breakthrough Curves to Evaluate the Economic Advantages of Chemical Regeneration of Activated Carbon in Power Plants: A Comparative Study
}

\author{
Thayset Mariño Peacok ${ }^{1}$, Harold Crespo Sariol ${ }^{2}$, Jeamichel Puente Torres ${ }^{3}$, Jan Yperman ${ }^{4, *} \mathbb{C}$, \\ Ángel Sánchez Roca ${ }^{5}$, Robert Carleer ${ }^{4}$ (i) and Liset Salomón García ${ }^{6}$ \\ 1 Faculty of Chemical Engineering, Applied Acoustic Laboratory, Universidad de Oriente, \\ Ave. Patricio Lumumba, 90500 Santiago de Cuba, Cuba; tpeacok@gmail.com \\ 2 Center of Neurosciences Signal and Images Processing, Applied Acoustic Laboratory, Universidad de Oriente, \\ Ave. Patricio Lumumba, 90500 Santiago de Cuba, Cuba; harold@uo.edu.cu \\ 3 Faculty of Electrical Engineering, Universidad de Oriente, Ave. Patricio Lumumba, \\ 90500 Santiago de Cuba, Cuba; jeamichelp@gmail.com \\ 4 Research Group of Applied and Circular Chemistry, Hasselt University, Agoralaan Building D, \\ 3590 Diepenbeek, Belgium; robert.carleer@uhasselt.be \\ 5 Faculty of Mechanical Engineering, Universidad de Oriente, Ave. Patricio Lumumba, \\ 90500 Santiago de Cuba, Cuba; sanchez@uo.edu.cu \\ 6 Electricity Generator Plant, National Highway km 26 1/2, 92300 Santiago de Cuba, Cuba; \\ lsalomongarcia@gmail.com \\ * Correspondence: jan.yperman@uhasselt.be; Tel.: +32-11-268295
}

Citation: Mariño Peacok, T.; Crespo Sariol, H.; Puente Torres, J.; Yperman, J.; Sánchez Roca, Á.; Carleer, R.; Salomón García, L. Mathematical Tool Based on Breakthrough Curves to Evaluate the Economic Advantages of Chemical Regeneration of Activated Carbon in Power Plants: A Comparative Study. Appl. Sci. 2021, 11,11786. https://doi.org/10.3390/ app112411786

Academic Editor: Jaecheul Yu

Received: 29 October 2021

Accepted: 3 December 2021

Published: 11 December 2021

Publisher's Note: MDPI stays neutral with regard to jurisdictional claims in published maps and institutional affiliations.

Copyright: $\odot 2021$ by the authors. Licensee MDPI, Basel, Switzerland. This article is an open access article distributed under the terms and conditions of the Creative Commons Attribution (CC BY) license (https:// creativecommons.org/licenses/by/ $4.0 /)$.
Abstract: A mathematical tool has been developed to evaluate the economic advantages of in-situ chemical regeneration of fixed-bed industrial adsorbers of granular activated carbon for cooling water treatment systems in Cuban power plants. Two scenarios of activated carbon (AC) management in a power plant were compared by applying the proposed model. The economic profit by implementing the regeneration strategy as a function of the number of regeneration cycles was determined and optimized. Breakthrough curves were obtained to assess the adsorption performance of the AC after progressive saturation-chemical regeneration cycles using synthetic water and hydrochloric acid, respectively. For the first saturation cycle, the breakthrough time was $272 \mathrm{~min}$ and after 10 cycles, it was reduced to $58 \mathrm{~min}$, indicating a decrease of the adsorption capacity of $21 \%$. The AC adsorption performance in terms of saturation time as a function of the number of regeneration cycles was considered one of the tool parameters. The proposed tool allows to determine the optimal number of regeneration cycles for a maximum economic profit in the regeneration strategy. It was demonstrated, using the proposed tool, that after an optimum of seven regeneration cycles, the power plant expends only $26 \%$ of the total investment. The simplicity of the tool permits a rapid way to find the most profitable number of regeneration cycles by combining economic, technical and adsorption efficiency parameters in one function, thus improving the AC management strategy at an industrial scale with corresponding environmental and economic advantages, including sustainability.

Keywords: granular-activated carbon; economic profit tool; regeneration; sustainability; water treatment

\section{Introduction}

Activated carbons (ACs) are the most widely used adsorbent material. Their adsorbent properties are essentially attributed to their large surface area, microporous structure, high adsorption capacity, a high degree of surface functionality and reactivity, and a favourable pore size distribution, which improves the accessible internal surface and enhances the adsorption rate [1]. ACs can be used in a powdered or granular form $(0.2-5 \mathrm{~mm})$. Granular activated carbons (GAC) are widely applied as an adsorbent in liquids in several industries, representing around $82 \%$ of total $\mathrm{AC}$ use. However, $\mathrm{AC}$ is one of the most popular and 
widely applied adsorbents for removing organic and inorganic pollutants from water resources (drinking (31\%) or ground (9\%)) and wastewater treatment (22\%) [2]. The global AC market size was estimated at USD 4.72 billion in 2018 and is expected to reach USD 14.66 billion by 2025. From 2019-2025, world AC consumption is projected to expand with $17.5 \%$ of GAC for water treatment and air purification [3].

The adsorption mechanisms of the AC results from interactions between the AC surface and the adsorbate. These interactions can be classified as electrostatic-if the adsorbate is an electrolyte and dissociates in an aqueous solution into ions (this interaction can be attractive or repulsive and depends on the $\mathrm{AC}$ charge density and $\mathrm{pH}_{\mathrm{PZC}}$, solution $\mathrm{pH}$ and ionic strength, and the adsorbate chemical characteristics) and ion exchange or nonelectrostatic (always attractive) and can include: (a) van der Waals forces, (b) hydrophobic interactions, (c) $\pi-\pi$ interactions and (d) hydrogen bonding) [4].

$\mathrm{AC}$ is known to be expensive including the environmental cost of the production/regeneration step. Therefore, identifying future promising alternative adsorbent materials is a key challenge for efficient yet affordable in the porous material industries. Nowadays, approaches have developed effective adsorbent materials such as graphene composites and transition metal carbides (MXene) with excellent performance and chemical and physical properties with the aim of adsorbing pollutants to improve the quality of effluents from productions processes [5-11]. Carbon-rich polymers are also another potential porous structure in material sciences with large specific surface areas and hierarchical porosities [12,13].

Consumption of ACs for industrial use has now become an indicator of development and environmental management efficiency. Management of AC constitutes four main steps: (1) Characterization, (2) Application/exploitation, (3) Exhaustion, and (4) Regeneration. Characterization of $\mathrm{AC}$ is required in the first step because the application (second step) will depend on the textural and chemical properties of the porous material. During application/exploitation of the AC, this material will reach an exhausted condition (third step, saturation of textural and chemical properties) [14]. Once exhausted, AC should be regenerated (fourth step) because of environmental, industrial and economic benefits (recycling spent $\mathrm{AC}$ rather than disposal and replacing it with virgin material is generally less expensive), contributing to sustainability [14-16]. AC regeneration has several advantages, including reduced solid waste handling problems (reuse of material, avoiding polluting the environment because of dumping activity, avoiding the production of new AC, cost lowering effect) [17-21]. Virgin-produced AC releases over eight times more carbon dioxide equivalents compared to regenerated AC. The potential for regeneration in any process turns into a comprehensive decrease of the environmental footprint [20]. The implementation of AC management in any industry should enable a strategy to permit the control, monitoring and performance optimization in the use of the adsorbent [14]. However, this practice is not implemented in all industries and especially not in developing countries.

In Cuba, the use of power plants is considered as Distributed Generation (DG) of electricity because it is an alternative method to centralize energy generation [22-25]. The main purpose of DG is to support the National Electro-energetic System (NES) during peak hours, where the consumption of electrical energy reaches a maximum value, and also to improve its transmission, especially in isolated regions.

During combustion in the engines, the energy obtained from fuel produces electricity and translates into useful work; the rest dissipates into heat and exhaust gases. The heat produced during the combustion reaction in the engine has to be dissipated and generally, water is used as a cooling medium [26]. Untreated water contains several compounds such as $\mathrm{CaCO}_{3}, \mathrm{Ca}\left(\mathrm{HCO}_{3}\right)_{2}, \mathrm{MgCO}_{3}, \mathrm{Mg}\left(\mathrm{HCO}_{3}\right)_{2}$, sulphates, nitrates and phosphates which can produce corrosion and incrustation and thereby affect the efficiency of the engines $[27,28]$. Therefore, power plants have a Water Treatment Unit (WTU) that improves the quality of the water (to guarantee the physical and chemical characteristics of the water feed) used in the cooling system (see Figure S1 in Supplementary information).

In the chemical regeneration of $A C$, certain specific chemical reagents are used to desorb or decompose the adsorbates [21,29-31]. Acidic and alkaline reagents, when used, 
dissolve the adsorbed inorganic substances based on their affinity for the reagents. Treatment with these chemicals may also affect the structure of the AC [21,30]. Although the efficiency of chemical regeneration depends on the type of contaminant in the spent AC, it also depends on the reactivity of the adsorbates and the AC with the chemical reagents [30]. Chemical regeneration is also applied to AC used in water treatment and is depending on the type of adsorbate. Acid washing is the chemical regeneration option, offering the most potential for remediation of accumulated metal ions and some of its carbonates on AC (being the main inorganic component in this research) [21,26,32-34]. Acid-leached samples attest to the fact that much of the calcium is removed via acid washing and therefore result in a lower $\mathrm{Ca}$ and ash content $[35,36]$.

The rapid small-scale column test (RSSCT) is an alternative to time-consuming and expensive plant studies [37]. RSSCTs use continuous-flow packed beds of adsorbent material that, through dimensionless analysis, can predict full-scale system performance in time [38]. The basic idea is to study the breakthrough behaviour in small columns that are specifically designed in a manner that guarantees that the operational conditions in the small-scale column reflect exactly the situation in the large-scale fixed-bed adsorber [37]. A major aspect of the RSSCT concept is then to transfer results produced with filters containing small-sized GAC to filters with larger sized GAC, for performance prediction [39].

One of the main units in the WTU is the GAC adsorbent, which adsorbs undesired compounds present in the water (organics, chlorine, $\mathrm{Ca}$ and $\mathrm{Mg}$ carbonates and metal ions). It has been demonstrated that the GAC filter removes ions of $\mathrm{Ca}, \mathrm{Al}, \mathrm{Fe}, \mathrm{Mn}$ and $\mathrm{Mg}$ in significant amounts during exploitation; however, $\mathrm{CaCO}_{3}$ is the calcium species present in the highest concentration in the GAC while organics are only present in trace amounts [40]. Recent publications demonstrate that the use of $\mathrm{HCl}$ can efficiently regenerate AC exhausted with the mentioned compounds [41].

In this work, two different scenarios in the power plant are compared using an economic tool which demonstrates the advantage of a correct GAC management strategy. In scenario one, regeneration of the exhausted GAC is applied instead of replacing it, leading, as will be proved, to a reduction in exploitation cost. In scenario two, after exhaustion, GAC is completely removed from the filter (causing a solid waste problem for the plant) and replaced by expensive virgin material.

\section{Materials and Methods}

\subsection{Target Scenarios in the Power Plant}

Scenario 1 implements regeneration of the GAC filter after the filter is declared as exhausted by specialists. Regeneration is performed using $7.4 \mathrm{wt} . \%(20 \%(v / v)) \mathrm{HCl}$. Scenario 2 does not implement regeneration and just purchase GAC-Virgin after two years of exploitation, which is the exploitation period of a virgin material (GAC-Virgin). The purchase of the GAC-Virgin is $6270 \mathrm{USD} /$ ton. In both scenarios, the same power plant is considered with equal technology for water treatment.

\subsection{GAC Samples}

In order to simulate scenario 1 at industrial scale, GAC-Virgin was used to perform experiments of adsorption and desorption at laboratory scale. This GAC-Virgin sample presents a surface area of $1288 \mathrm{~m}^{2} / \mathrm{g}, 0.536$ and $0.453 \mathrm{~cm}^{3} / \mathrm{g}$ of total pore and micropore volume, respectively. Its apparent density is $535 \mathrm{~kg} / \mathrm{m}^{3}$, the ash content is $3.45 \%$ and the average particle size is $1.2 \mathrm{~mm}$. On the other hand, exhausted GAC was used in order to study dynamic regeneration. The surface area, total pore volume and micropore volume of the exhausted GAC sample (GAC-Exh) are $196 \mathrm{~m}^{2} / \mathrm{g}, 0.103 \mathrm{~cm}^{3} / \mathrm{g}$ and $0.077 \mathrm{~cm}^{3} / \mathrm{g}$, respectively, and its ash content is $25.59 \%$ [40].

\subsection{Synthetic Water}

Synthetic water was produced according to the Standard Operating Procedure for preparation of hard water and other diluents for antimicrobial products [42]. Briefly, two 
water solutions with different hardness were prepared. Solution 1: dissolving $16.94 \mathrm{~g}$ $\mathrm{MgCl}_{2} \bullet 6 \mathrm{H}_{2} \mathrm{O}$ and $18.50 \mathrm{~g} \mathrm{CaCl}_{2}$ in boiled Milli-Q water and diluted in a $250 \mathrm{~mL}$ volumetric flask; and solution 2: dissolving $14.01 \mathrm{~g} \mathrm{NaHCO}_{3}$ in boiled Milli-Q water and bringing to a volume of $250 \mathrm{~mL}$. The corresponding amount of hard water solutions 1 and 2 were diluted in $1 \mathrm{~L}$ volumetric flask according to the desired total hardness, expressed in $\mathrm{mg}$ $\mathrm{CaCO}_{3} / \mathrm{L}$. In this research, synthetic water with a total hardness of $500 \mathrm{mg} \mathrm{CaCO} / \mathrm{L}$ was applied. This high total hardness (comparable with the industrial water to be treated [40]) was used with the aim of obtaining shorter saturation times during the exhaustion of the GAC in order to validate the proposed economic tool.

\subsection{Adsorption (Exhaustion) Experiments}

Calcium was the major element in the exhausted GAC samples applied in this power plant [40]; therefore, to simulate the process of exhaustion in laboratory conditions, synthetic water was used to saturate the GAC samples. The solutions were prepared according to Section 2.3. Hereafter, GAC exhausted samples were washed with Milli-Q water. Each time in which the exhaustion condition was reached, it is considered a "complete saturation cycle" of the GAC used.

\subsection{Desorption (Regeneration) Experiments}

Exhausted GAC was regenerated using $\mathrm{HCl}$ under laboratory conditions. Solutions were prepared by diluting the original reagent (commercial $37 \mathrm{wt} . \% \mathrm{HCl}$ ) into Milli-Q water to obtain a solution of $7.4 \mathrm{wt} . \% \mathrm{HCl}$. In order to know the dynamic conditions of regeneration of the exhausted GAC sample, the performance of breakthrough curve was evaluated every $20 \mathrm{~min}$. The industrial regeneration strategy used in scenario 1 is based on these results.

After exhaustion of the virgin GAC using synthetic water, the acid reagent was used for the regeneration of the exhausted GAC and to study the number of adsorption/desorption cycles of the virgin GAC.

\subsection{Scaling down the GAC Water Filter}

The relation between the diameters $\left(R_{D}\right)$ and length $\left(R_{H}\right)$ of the columns, known as scale factor, was kept constant in the laboratory and industrial columns following Equations (1)-(4) [43-46]:

$$
R_{D}=\frac{D}{d}
$$

where:

D: Industrial filter diameter; in $\mathrm{mm}$

d: GAC particle diameter; $1.2 \mathrm{~mm}$

For scaling and obtaining GAC particle diameter $(d \prime)$ for laboratory experimental conditions, Equation (2) was used:

$$
R_{D}=\frac{D^{\prime}}{d^{\prime}}
$$

where:

$D^{\prime}$ : Experimental column diameter, in $\mathrm{mm}$

For the length of column, Equation (3) was applied:

$$
R_{H}=\frac{D}{H}
$$

where:

$H$ : Industrial filter length in $\mathrm{mm}$

For scaling and obtaining the length of column $\left(h^{\prime}\right)$ for laboratory experimental conditions, Equation (4) was used.

$$
R_{H}=\frac{D^{\prime}}{h^{\prime}}
$$


The mass of GAC ( $\left.m_{\mathrm{GAC}}\right)$ to perform the experiments is an important parameter for obtaining correct results during dynamic regeneration. It depends on the experimental volume of GAC $\left(V_{e}\right)$ needed in the experiments. Both parameters are calculated using Equations (5) and (6). Table 1 summarizes all the parameter values used in the geometric scaling.

$$
\begin{gathered}
V_{\text {exp }}=\pi \cdot \frac{D^{\prime 2}}{4} \cdot h^{\prime} \\
m_{G A C, \exp }=\rho_{\exp } \cdot V_{\exp }
\end{gathered}
$$

where:

Table 1. Parameters used in the geometric scaling.

\begin{tabular}{cccc}
\hline Parameter & Value & Parameter & Value \\
\hline $\mathrm{D}(\mathrm{mm})$ & 480 & $\mathrm{~V}_{\exp }\left(\mathrm{m}^{3}\right)$ & $1.78 \times 10^{-5}$ \\
$\mathrm{~d}(\mathrm{~mm})$ & 1.2 & $\mathrm{~m}_{\mathrm{G} A C-\operatorname{Exh}, \exp }(\mathrm{g})$ & 8.16 \\
$\mathrm{D}^{\prime}(\mathrm{mm})$ & 25 & $\rho_{G A C-E x h, \exp }\left(\mathrm{kg} \cdot \mathrm{m}^{-3}\right)$ & 456.5 \\
$\mathrm{~d}^{\prime}(\mathrm{mm})$ & 0.063 & $\mathrm{~m}_{G A C-\text { Virgin,exp }}(\mathrm{g})$ & 5.18 \\
$\mathrm{H}(\mathrm{mm})$ & 700 & $\rho_{G A C-\text { Virgin, } \exp }\left(\mathrm{kg} \cdot \mathrm{m}^{-3}\right)$ & 313.7 \\
$\mathrm{~h}^{\prime}(\mathrm{mm})$ & 36.46 & & \\
\hline
\end{tabular}

$\rho_{\text {exp }}$ : Apparent density of the experimental powder AC used (for a particle size of $0.063 \mathrm{~mm}$ ); kg.m ${ }^{-3}$ (determined by ASTM D 2854-96 [47]).

\subsection{Breakthrough Curves}

The performance of fixed bed is described through the concept of the breakthrough curve. The time and the shape of the breakthrough curves are very important characteristics for determining the operation and dynamic response of an adsorption column. Prediction of breakthrough curve is the predominant factor for the successful design/evaluation of a column in an adsorption/desorption process [48].

\section{Desorption and Adsorption Experiments}

A diagram of the experimental set-up used for breakthrough curve study is shown in Figure 1. Briefly, from the beaker, (1) using a Heidolph Pump drive 5001 peristaltic pump (tubing size: $1.5 \mathrm{~mm}$ ), (2) the $\mathrm{HCl}$ solution was fed to the experimental column (glass tube with 2.5-centimetre diameter and 6-centimetre height of powder AC column) (3) which contain the AC particles (4) (0.063 mm diameter) and quartz sand (5). After elution, the effluent was collected in a beaker (6). At regular time intervals (15 min (conductivity) and $20 \mathrm{~min}(\mathrm{pH})), 1 \mathrm{~mL}$ solution was sampled and transferred to a measurement beaker (11) and diluted (1:100). The $\mathrm{pH}$ and the conductivity of the diluted effluent were measured using PHSJ-4A pH meter (7) and a pH electrode (8) (Figure 1a) and using a conductivity meter Inolab Cond 7110 (9) and conductivity measuring cell (10) (Figure 1b), respectively into the sample dilution beaker (11). The flow rate of the acid and the synthetic water solution was $0.1 \mathrm{~mL} / \mathrm{min}$, which is low enough, thus potentiating intra-particle diffusion process, and the external mass transfer will control the adsorption/desorption mechanism [48]. Experiments were continued until the column reached a constant $\mathrm{H}^{+}$concentration (equal to the initial $\mathrm{H}^{+}$concentration of the $\mathrm{HCl}$ solution) or a constant initial conductivity and were carried out at room temperature $\left(25 \pm 2{ }^{\circ} \mathrm{C}\right)$. 
1. Solution feed storage

2. Peristaltic Pump

3. Fixed bed adsorber

4. Activated carbon

5. Quartz sand

6. Sample collector

7. $\mathrm{pH}$ meter

8. Electrode

9.Conductivity meter

10.Conductivity measuring cell

11. Sample dilution
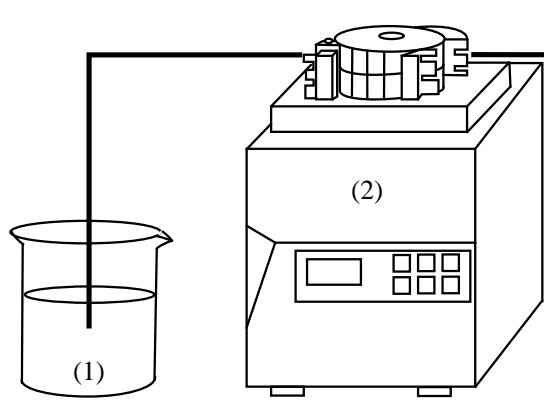
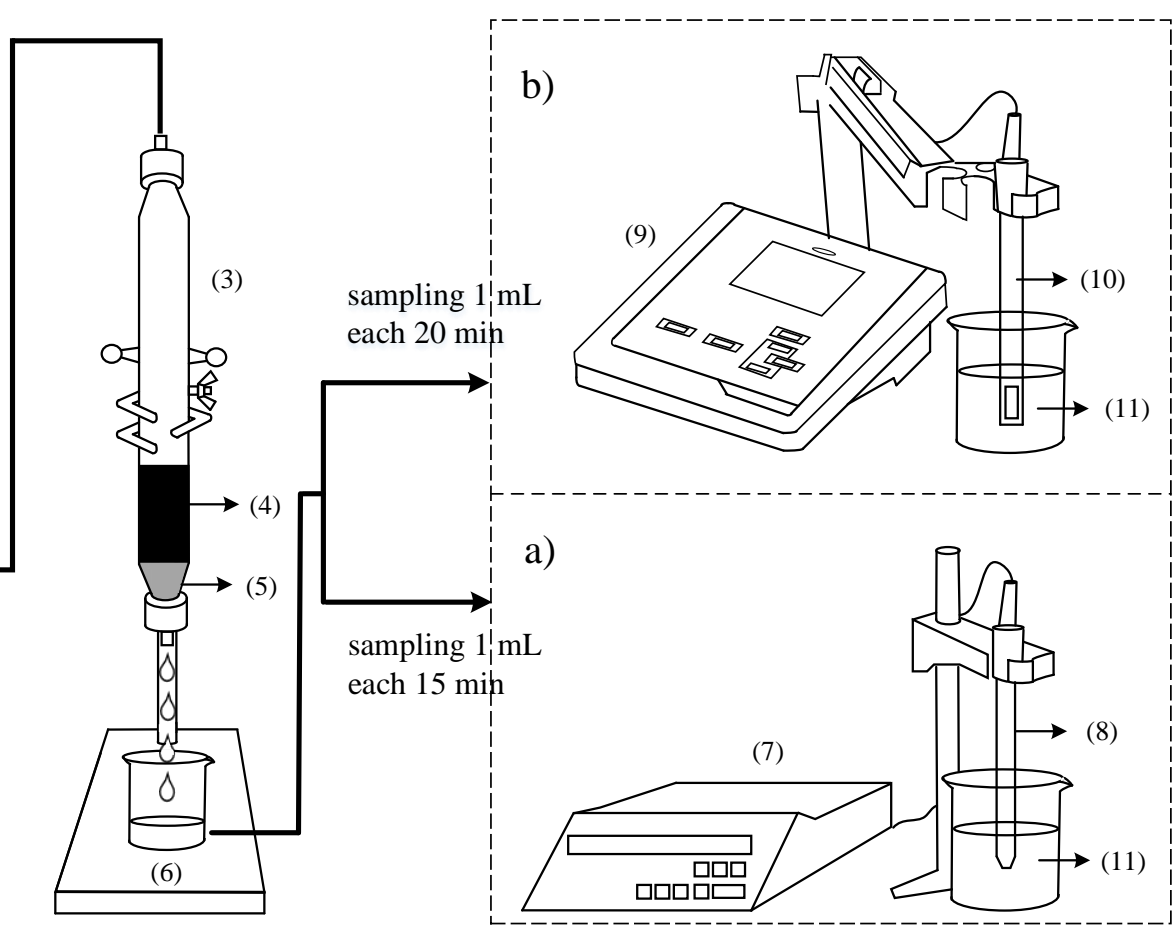

Figure 1. Schematic diagram of the experimental set-up used for the dynamic (a) regeneration and (b) exhaustion study.

Procedure to construct the breakthrough curve using $\mathrm{pH}$ measurements:

I. Measurement of the $\mathrm{pH}$ of the solution: (1) original solution of $7.4 \mathrm{wt} . \% \mathrm{HCl}$ giving $c\left(\mathrm{H}^{+}\right)_{0}$ (initial concentration of $\mathrm{H}^{+}$); (2) every $20 \mathrm{~min}$, sampling $1 \mathrm{~mL}$ of the effluent after elution through GAC; (3) sample was diluted into $100 \mathrm{~mL}$ of Milli-Q water to measure the $\mathrm{pH}$ (results are displayed in Table 2).

II. The equivalent law is applied according to Equation (7) to determine the actual concentration of the $\mathrm{H}^{+}$ions in the initial solution $\left(c\left(\mathrm{H}^{+}\right)_{i}\right)$ using the measured $\mathrm{H}^{+}$ ions concentration in the diluted solution $\left(c\left(H^{+}\right)_{f}\right)$.

$$
c\left(H^{+}\right)_{i} \cdot V_{i}=c\left(H^{+}\right)_{f} \cdot V_{f}
$$

where: $V_{i}=1 \mathrm{~mL}$ (initial volume) and $V_{f}=100 \mathrm{~mL}$ (final volume).

III. Construction of the breakthrough curve $\left(c\left(H^{+}\right)_{i} /\left(c\left(H^{+}\right)_{0}\right)\right.$ versus time.

Table 2. Initial conductivity, $\mathrm{pH}$ and $\mathrm{H}^{+}$ion concentration for performing the adsorption and desorption experiments respectively.

\begin{tabular}{ccc}
\hline & \multicolumn{2}{c}{ Reagent Concentration } \\
\cline { 2 - 3 } Property & Synthetic Water (Adsorption) & HCl (Regeneration) \\
\cline { 2 - 3 } & $\mathbf{5 0 0 ~} \mathbf{~} \mathbf{~ C a C O}_{3} / \mathbf{L}$ & $\mathbf{7 . 4} \mathbf{~ w t . \%}$ \\
\hline Conductivity, $\mu \mathrm{S} / \mathrm{cm}$ & 1468 & 619 \\
$\mathrm{pH}$ & 7.89 & $1.91 *$ \\
$c\left(H^{+}\right)_{0},(\mathrm{mg} / \mathrm{L})$ & $1.29 \times 10^{-8}$ & 1.262 \\
\hline
\end{tabular}

* after dilution 1:100.

However, after exhaustion with the synthetic water, for the desorption experiments using $7.4 \mathrm{wt}$ \% $\mathrm{HCl}$, equilibrium was reached when the $c\left(\mathrm{H}^{+}\right)_{f}$ of the effluent is finally equal to $c\left(H^{+}\right)_{0}$ of the $7.4 \mathrm{wt}$.\% $\mathrm{HCl}$ solution.

Procedure to construct the adsorption breakthrough curve using conductivity: 
I. Relationship between hardness of synthetic water (in $\mathrm{mg} \mathrm{CaCO}_{3} / \mathrm{L}$ ) and the conductivity (in $\mu \mathrm{S} / \mathrm{cm}$ ) results in a calibration curve with excellent linear relationship with high regression coefficient of $99.17 \%$ (see Figure 2).

II. Conductivity measurements: every $15 \mathrm{~min}, 1 \mathrm{~mL}$ of the effluent solution of the eluent passing through GAC was sampled and diluted into $100 \mathrm{~mL}$ of Milli-Q water to measure the conductivity. Initial solution properties are displayed in Table 2.

III. The equivalent law is applied according to Equation (8) to determine the real hardness $c_{f}$ of the synthetic water solution (in $\mathrm{mg} \mathrm{CaCO}_{3} / \mathrm{L}$ ) as function of time:

$$
c_{i} \cdot V_{i}=c_{f} \cdot V_{f}
$$

where: $c_{i}=$ hardness of the dilute solution after filtration; $c_{f}=$ real hardness after filtration; $V_{i}=1 \mathrm{~mL}$ (initial volume) and $V_{f}=100 \mathrm{~mL}$ (final volume).

IV. Construction of the breakthrough curve using the following relation: $\mathrm{C} / \mathrm{C}_{\mathrm{o}}$ (water hardness after filtration)/(initial water hardness) versus time.

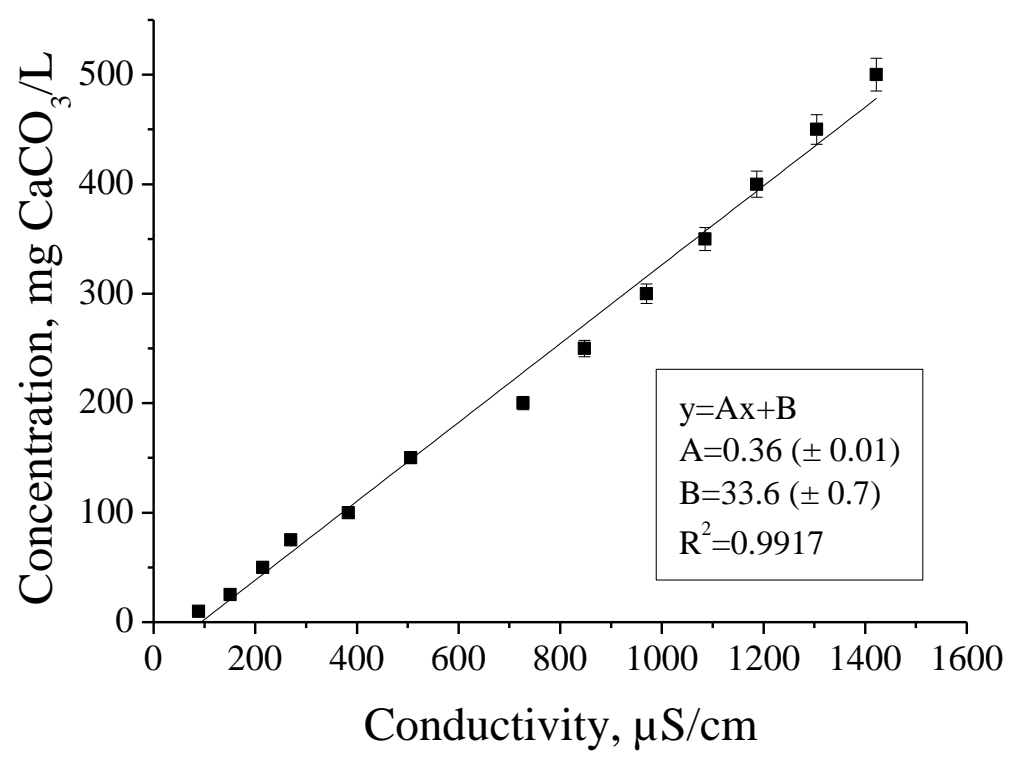

Figure 2. Calibration curve of hardness of synthetic water solutions (in $\mathrm{mg} \mathrm{CaCO}_{3} / \mathrm{L}$ ) as a function of the conductivity (in $\mu \mathrm{S} / \mathrm{cm}$ ).

\section{Results and Discussion}

\subsection{Dynamic Regeneration of Exhausted GAC}

Following the scaling rules for scaling down the water filter (see Section 2.6), a dynamic regeneration was performed. Figure 3a displays the regeneration breakthrough curve using 7.4 wt.\% $\mathrm{HCl}$ after applying RSSCT experiments. The breakthrough time was determined as the desorption time for reaching the equilibrium concentration at which $c\left(\mathrm{H}^{+}\right)_{i} /\left(c\left(\mathrm{H}^{+}\right)_{0}\right.$ equals 0.05 . This ratio was chosen, reducing the amount of $\mathrm{HCl}$ needed for regeneration and thus lowering the cost of this process in a real power plant installation. The breakthrough curve using $7.4 \mathrm{wt} . \% \mathrm{HCl}$ shows a sharp and relatively fast transition during the regeneration, indicative of a high desorption rate with a breakthrough time of $184 \mathrm{~min}$, as shown in Figure 3. $\mathrm{HCl}$ reacts with the adsorbed compounds on the GAC particles (mainly $\mathrm{CaCO}_{3}$ ), leading to a fast regeneration of the $\mathrm{GAC}$ in the column. $\mathrm{HCl}$ breakthrough curve presents a slightly narrow mass-transfer zone, and as a result, the desorption capacity increases. 

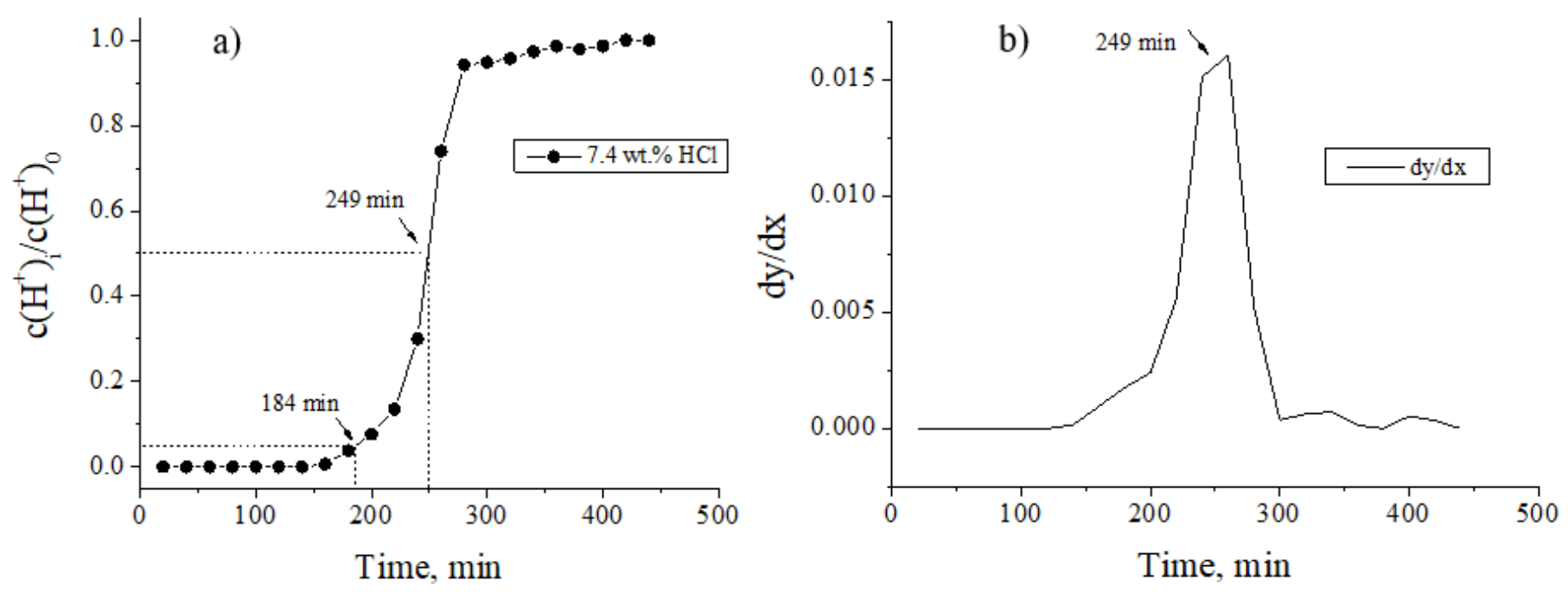

Figure 3. (a) Breakthrough curve for $7.4 \mathrm{wt} . \% \mathrm{HCl}$ during dynamic regeneration of GAC-Exh using RSSCT experiments;

(b) derivative function of the breạkthrough curve. $\frac{d y}{d x}=\frac{d\left(\frac{c\left(H^{+}\right)_{i}}{c\left(H^{+}\right)_{0}}\right)}{d t}$.

\subsection{Economic Tool to Evaluate the Advantages of Regeneration}

The volume of chemical regeneration agent of $37 \mathrm{wt} . \% \mathrm{HCl}\left(V_{\mathrm{HCl}, 37 \%}\right)$ consumed at industrial scale and its respective chemical regeneration cost $\left(P_{r}\right)$ can be calculated based on Equations (9) and (10), respectively:

$$
\begin{gathered}
V_{H C l, 37 \%}=\frac{Q_{H C l, \exp } \cdot t_{o p}}{m_{G A C, \exp }} \cdot m_{G A C} \cdot \frac{7.4 w t . \%}{\delta} \\
P_{r}=V_{H C l, 37 \%} \cdot P_{H C l}
\end{gathered}
$$

where:

$Q_{H C l, \text { exp }}$ : experimental flow of $\mathrm{HCl}, 1 \times 10^{-4} \mathrm{~L} / \mathrm{min}$ at laboratory conditions.

$t_{o p}$ : operation time for chemical regeneration equilibrium determined by the breakthrough curve, 249 min (Figure 3a).

$m_{G A C \text {, exp }}$ : experimental mass of powder $\mathrm{AC}$ in the experimental column, $8.16 \mathrm{~g}$

$m_{G A C}:$ mass of GAC in the fixed-bed industrial filter, $1 \times 10^{6} \mathrm{~g}$

$\delta: \mathrm{HCl}$ purity, 37 wt.\%

$P_{H C l}$ : Bulk HCl price, (in \$/L).

The bulk $\mathrm{HCl}$ price is USD 196 for $250 \mathrm{~kg}$ of $37 \mathrm{wt} \% \mathrm{HCl}$ [49]; therefore, the price of $\mathrm{HCl}$ per volume unit can be estimated according to Equations (11) and (12):

$$
\begin{aligned}
V_{H C l, 37 w t . \%} & =\frac{m_{H C l, 37 w t . \%}}{\rho_{H C l}, 37 w t . \%} \\
P_{H C l}(\$ / L) & =\frac{\$ 196}{V_{H C l, 37 w t . \%}}
\end{aligned}
$$

where:

$\rho_{\mathrm{HCl}, 37 w t . \%}$ : density of $\mathrm{HCl} 37 \mathrm{wt} . \% ; 1.19 \mathrm{~kg} / \mathrm{L}$.

$m_{\mathrm{HCl}, 37 w t . \%}$ : mass of $\mathrm{HCl} 37 \mathrm{wt} \%$; in $\mathrm{kg}$.

$V_{\mathrm{HCl}, 37 w t . \%}$ : volume of $\mathrm{HCl} 37$ wt.\%; in L.

Finally, $P_{\mathrm{HCl}}=0.9330 \mathrm{USD} / \mathrm{L}(=\mathrm{USD} 196.1 .19 \mathrm{~kg} / \mathrm{L}) / 250 \mathrm{~kg}$

Applying Equation (9);

$$
V_{H C l, 37 \%}=\frac{0.1 \cdot 10^{-3} \cdot 249}{8.16} \cdot 10^{6} \cdot \frac{7.4}{37}=610 \mathrm{~L} / \mathrm{ton}
$$


Then from Equation (10)

$P_{r}=0.9330 \$ / L \cdot 610 \mathrm{~L} /$ ton $=569.4 \mathrm{USD} /$ ton of GAC regenerated.

On the other hand, the initial cost of purchasing the amount of virgin GAC $\left(P_{0}\right)$ can be calculated by Equation (13):

$$
P_{o}=m_{G A C} \cdot P_{v}
$$

where

$P_{v}$ : GAC-Virgin purchasing cost, USD/ton. The current total purchasing cost of the GAC-Virgin for power plants is $6270 \mathrm{USD} /$ ton, including shipping and transportation costs [49].

In order to analyse the economic benefits by applying the chemical regeneration strategy in the power plant for scenario one compared with scenario two, the ratio $\left(\frac{C_{r, 1}}{C_{w, 2}}\right)$ (Equation (14)) was used as parameter for the economical assessment, and it can be applied as follows:

$0<\left(\frac{C_{r, 1}}{C_{w, 2}}\right) \leq 1$ Economically feasible : the closer to zero, the higher is the profit.

$$
\left(\frac{C_{r, 1}}{C_{w, 2}}\right)=1 \text { Breakout. }
$$

$$
\left(\frac{C_{r, 1}}{C_{w, 2}}\right)>1 \text { Economically not feasible. }
$$

where:

$C_{r, 1}$ : cost of the GAC management with regeneration strategy in scenario one (in $\mathrm{USD} /$ year)

$C_{w, 2}$ : cost of the GAC management in scenario two without regeneration and replacing filter by new batch of GAC-Virgin when exhaustion occurs (in \$/year)

In scenario two, GAC-Exh from the filter is replaced with virgin material at a purchasing $\operatorname{cost} P_{0}$, which in turn will be exhausted after a specific saturation time $t_{s v}$, for a number of " $\mathrm{n}$ " exhaustion/replacement cycles. Then, $C_{w, 2}$ can be calculated according to Equation (17):

$$
C_{w, 2}=\frac{P_{o_{1}}+P_{o_{2}}+\ldots P_{o_{n}}}{t_{s v_{1}}+t_{s v_{2}}+\ldots t_{s v_{n}}}
$$

$P_{o_{n}}:$ Purchasing cost of GAC-Virgin for replacement of the GAC-Exh in an exploitation cycle " $\mathrm{n}$ " (in \$).

$t_{s v_{n}}$ : Saturation or exhaustion time for GAC-Virgin of an exploitation cycle " $\mathrm{n}$ " (in years).

Considering that the purchasing cost of GAC-Virgin is the same; thus,

$$
P_{o_{1}}=P_{o_{2}}=\ldots P_{o_{n}}
$$

If the inlet water quality to the filter and the filter operation parameters do not change significantly then the saturation/exhaustion time will not change;

$$
t_{s v_{1}}=t_{s v_{2}}=\ldots t_{s v_{n}}
$$

Under that condition, Equation (17) can be rewritten as:

$$
C_{w, 2}=\frac{\sum_{0}^{n_{c}} P_{o_{i}}}{\sum_{0}^{n_{c}} t_{s v_{i}}}=\frac{n_{c} \cdot P_{o}}{n_{c} \cdot t_{s v}}=\frac{P_{o}}{t_{s v}}
$$

where

$n_{c}$ : number of replacement cycles (dimensionless)

$t_{s v}$ : saturation time of GAC-Virgin (in years) 
In this specific case, the saturation or exhaustion time $t_{s v}$ is two years for the GACVirgin under study. Therefore, for the strategy of scenario two, the cost $C_{w, 2}$ has a constant value according to Equation (21).

$$
C_{w, 2}=\frac{P_{0}}{t_{s v}}=\frac{6270 \cdot 1}{2}=3135 \$ / \text { year }
$$

In contrast, for the chemical regeneration strategy implemented in scenario one, the cost $C_{r}$ can be then expressed by Equation (22).

$$
C_{r, 1}=\frac{P_{o}+\left(P_{r_{1}}+P_{r_{2}}+\ldots P_{r_{n}}\right)}{t_{s v}+\left(t_{s r_{1}}+t_{s r_{2}}+\ldots t_{s r_{n}}\right)}
$$

For scenario one, there is an initial investment process of purchasing GAC-Virgin $\left(P_{o}\right)$ to fill the industrial adsorber of 1 ton of capacity. According to the virgin condition of the GAC, the saturation/exhaustion time is $t_{s v}$. After the first two years of exploitation, the GAC in the filter becomes exhausted. However, a regeneration strategy is implemented in scenario one, and the investment to perform the first chemical regeneration process of GACExh is $P_{r_{1}}$ (in USD); thus $P_{r_{n}}$ is the investment for " $\mathrm{n}$ " regeneration cycles. Correspondently, $t_{s r_{1}}$ to $t_{s r_{n}}$ are the saturation/exhaustion times of the GAC regarding the first to " $\mathrm{n}$ " chemical regeneration cycles.

If the regeneration process occurs under the same operational conditions of $\mathrm{HCl}-\mathrm{GAC}$ contact, $\mathrm{HCl}$ flow, retention time and the amount of $\mathrm{HCl}$ solution applied is the same, investment cost will also remain the same; thus,

$$
P_{r_{1}}=P_{r_{2}}=\ldots P_{r_{n}}
$$

Therefore,

$$
\left(P_{r_{1}}+P_{r_{2}}+\ldots P_{r_{n}}\right)=\sum_{0}^{n_{i}} P_{r_{i}}=n_{i} \cdot P_{r}
$$

where

$P_{r_{i}}$ : Investment cost for chemical regeneration in an " $\mathrm{i}$ " regeneration cycle (in USD)

$n_{i}$ : Number of chemical regeneration cycles (dimensionless)

On the contrary, compared with GAC-Virgin where saturation time $\left(t_{s v}\right)$ is a constant parameter, the saturation/exhaustion time after each regeneration cycle will be different. After each chemical regeneration cycle, the efficiency of adsorbates removal from the GAC pores decays which in turn progressively reduces the adsorption capacity of the adsorbent.

In that case, $t_{s r_{1}}>t_{s r_{2}}>t_{s r_{3}}>\ldots t_{s r_{n}} t_{s r_{i}}$ : Saturation time of the regenerated GAC after the " $\mathrm{i}$ " regeneration cycle (in years)

However, taking as reference the saturation time of the virgin GAC, the exploitation time of a regenerated GAC after an " $\mathrm{i}$ " regeneration cycle $\left(t_{s r_{i}}\right)$ can be expressed as a fraction of the saturation time of virgin material $\left(t_{s v}\right)$, and it can be defined using Equation (25):

$$
t_{s r_{i}}=x_{i} \cdot t_{s v}
$$

where

$x_{i}$ : Fractional saturation time of a regenerated GAC in the regeneration cycle " $\mathrm{i}$ " in terms of the saturation time of the virgin material. Then,

$$
\left(t_{s r_{1}}+t_{s r_{2}}+\ldots t_{s r_{n}}\right)=t_{s v} \cdot \sum_{0}^{n_{i}} x_{i}
$$

Taking into account the progressive loss of adsorption capacity after each regeneration cycle and also the higher adsorption capacity of GAC-Virgin compared to the regenerated GAC, it is logical to expect that the saturation time of the regenerated GAC will progressively decrease in comparison with the saturation time of GAC-Virgin. 
Combining Equations (22), (24) and (26) for the regeneration cost gives:

$$
C_{r, 1}=\frac{P_{o}+n_{i} \cdot P_{r}}{t_{s v} \cdot\left(1+\sum_{0}^{n_{i}} x_{i}\right)}
$$

Thus, combining Equations (20) and (27) an economic index for comparing GAC management strategies in both scenarios $\left(\frac{C_{r, 1}}{C_{w, 2}}\right)$ is obtained:

$$
\left(\frac{C_{r, 1}}{C_{w, 2}}\right)=\frac{\left[1+n_{i}\left(\frac{P_{r}}{P_{o}}\right)\right]}{\left(1+\sum_{0}^{n_{i}} x_{i}\right)}
$$

According to the proposed model in Equation (28), the feasibility of the regeneration strategy is reduced by increasing the number of regeneration cycles $\left(n_{i}\right)$ and the regeneration investment $\left(P_{r}\right)$. On the other hand, reduction of the fractional saturation time $\left(x_{i}\right)$ after each regeneration also diminishes the economic profit of the regeneration strategy. For an ideal situation, if the saturation time of the regenerated GAC is comparable to the saturation time of GAC-Virgin $\left(x_{i} \cong 1\right)$, the ratio $\left(\frac{C_{r, 1}}{C_{w, 2}}\right)$ will remain below " 1 " and the regeneration will always be economically profitable as long as the regeneration process and the virgin material purchasing costs remain without significant changes during the water purification process.

However, as it has been reported in several publications [50-54] and also demonstrated further on in this paper, during each regeneration cycle, the adsorption capacity of the GAC diminished. In that case, there is a correlation between the number of regeneration cycles and the decreasing fractional saturation time $\left(x_{i}=f\left(n_{i}\right)\right)$ in a sort of a "regeneration performance equilibria data" (RPED) for specific regeneration process conditions which can be obtained experimentally, as will be explained in Section 3.3.

\subsection{Exhaustion-Regeneration Performance Equilibria}

GAC-Virgin was submitted to saturation (synthetic water, $500 \mathrm{mg} \mathrm{CaCO} / \mathrm{L}$ ) and regeneration cycles (using $7.4 \mathrm{wt} . \% \mathrm{HCl}$ ), as outlined in Figure 1. The target species to be adsorbed and chemically desorbed is $\mathrm{Ca}^{2+}$ since it is present as major adsorbed species on the GAC surface and thus most responsible for GAC saturation during water treatment in this process. Therefore, a synthetic water solution was used to saturate the GAC and after saturation, $7.4 \mathrm{wt} . \% \mathrm{HCl}$ solution is used to regenerate the GAC. As explained in Section 2.7 , the adsorption and regeneration processes were monitored by the breakthrough curves using conductivity or $\mathrm{pH}$ as monitoring parameters respectively.

Figure 4 displays the different synthetic water adsorption breakthrough curves obtained for the GAC filter after each regeneration cycle. These results allow us to obtain the performance in terms of saturation time for the regenerated GAC $\left(t_{s r}\right)$ for each regeneration cycle. The first exhaustion performance corresponds to the maximum saturation time of GAC-Virgin $\left(t_{s v}\right)$, which will be the reference value for calculating the fractional saturation time for each subsequent regeneration. In this case, $t_{s v}=272 \mathrm{~min}$, taking the ratio $c\left(\mathrm{Ca}^{2+}\right)_{\mathrm{i}} / \mathrm{c}\left(\mathrm{Ca}^{2+}\right)_{\mathrm{O}}=0.5$ as a reference point in the breakthrough curve of GAC-Virgin, as shown in Figure 4.

As expected, it is confirmed from Figure 4 that $t_{s r}$ decreases with the number of regeneration cycles $n_{i}$ due to the cumulative loss of GAC adsorption capacity after each regeneration cycle. It can be noticed that after 10 regeneration cycles, the GAC performance is significantly reduced being already saturated in around $58 \mathrm{~min}$, thus representing around $21 \%$ of the saturation time performance of the virgin material. 


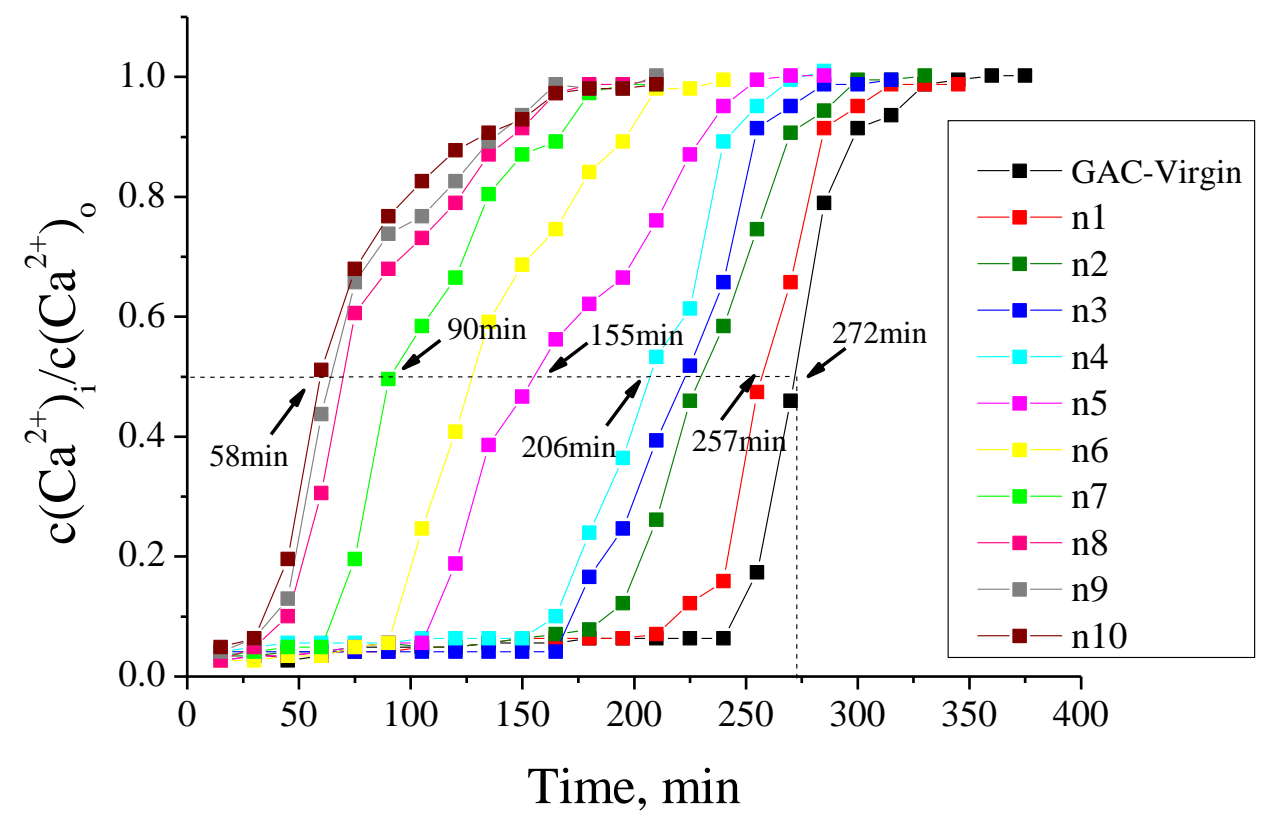

Figure 4. Breakthrough curves after different number of regeneration cycles $\left(\mathrm{n}_{\mathrm{i}}\right)$ and virgin GAC exhaustion. $\mathrm{c}\left(\mathrm{Ca}^{2+}\right)_{\mathrm{i}} / \mathrm{c}\left(\mathrm{Ca}^{2+}\right)_{\mathrm{o}}$ (water hardness after filtration)/(initial water hardness).

\subsection{Economic Assessment Based on the Proposed Tool}

Based on the experimental results, the economic criteria $\left(\frac{C_{r, 1}}{C_{w, 2}}\right)$ by applying Equation (28) resulted in the data depicted in Table 2. From Table 2, the first value of $\left(\frac{C_{r, 1}}{C_{w, 2}}\right)=1$, since both scenarios one and two need to purchase the same amount of GAC-Virgin and any regeneration has not been performed yet $\left(n_{i}=0\right)$. In addition, both scenarios are using GAC-Virgin till exhaustion after two years of exploitation and cost for both scenarios are the same within this period. The function $\sum_{0}^{n_{i}} x_{i}$ can be calculated by Equation (29).

$$
\sum_{0}^{n_{i}} x_{i}=x_{n i-1}+\sum_{0}^{n_{i}-1} x_{i}
$$

Equation (29) mathematically corrects the loss in exploitation duration (no loss when $x_{i}=1$ ) when regenerated GAC is used. This loss is defined by calculating the ratio of the exploitation time of a GAC-Exh after a regeneration cycle $n_{i}$ and the exploitation time of GAC-Virgin. It is clear that after each regeneration, this $x_{i}$ value decreased. In Table 3 , the calculation process of $\sum_{0}^{n_{i}} x_{i}$ is indicated by arrows as a simplified scheme for the first case. When $n_{1}, x_{1}=0.94$, this value represents the ratio of breakthrough time for GAC-Exh divided by the breakthrough time for GAC-Virgin (Equation (25)). 
Table 3. Parameters for the calculation of optimal number of regeneration cycles to maximize economic profit.

\begin{tabular}{|c|c|c|c|c|c|c|c|}
\hline & $n_{i}$ & $t_{r s}(\mathrm{Min})$ & $x_{i}$ & & $\sum_{0}^{n_{i}}\left(x_{i}\right)$ & $\frac{C_{r, 1}}{C_{w, 2}}$ & $\frac{d\left(\frac{C_{r, 1}}{C_{w_{v}, 2}}\right)}{d\left(\sum_{0}^{\sum_{i}} x_{i}\right)}$ \\
\hline & 0 & 272 & 1.00 & \multirow{7}{*}{+} & 0.00 & 1.000 & -0.455 \\
\hline & 1 & 257 & 0.94 & & 1.00 & 0.545 & -0.153 \\
\hline & 2 & 223 & 0.85 & & 1.94 & 0.401 & -0.078 \\
\hline & 3 & 222 & 0.82 & & 2.79 & 0.336 & -0.049 \\
\hline & 4 & 206 & 0.76 & & 3.61 & 0.296 & -0.033 \\
\hline & 5 & 155 & 0.57 & & 4.36 & 0.271 & -0.019 \\
\hline & 6 & 128 & 0.47 & & 4.93 & 0.260 & -0.011 \\
\hline \multirow[t]{4}{*}{$n_{i}$} & 7 & 90 & 0.33 & & 5.40 & 0.255 & 0.003 \\
\hline & 8 & 70 & 0.26 & & 5.74 & 0.256 & 0.014 \\
\hline & 9 & 64 & 0.24 & & 5.99 & 0.260 & 0.017 \\
\hline & 10 & 58 & 0.21 & & 6.23 & 0.264 & - \\
\hline
\end{tabular}

$n_{i}{ }^{*}$ Optimal number of regenerations.

Analysing the behaviour of the $\left(\frac{C_{r, 1}}{C_{w, 2}}\right)$ function at studied conditions, the regeneration investment is quite low compared with the purchasing cost of the virgin material (just around $9.1 \%$ of the purchasing cost of virgin material $=>569.4 / 6270$ ) for ten regenerations cycles and the ratio $\left(\frac{C_{r, 1}}{C_{w, 2}}\right)$ is still below the breakout line $\left(\frac{C_{r, 1}}{C_{w, 2}}\right)=1$ thus suggesting that the process is economically favourable even when the performance of the regenerated GAC after ten regenerations is significantly deteriorated. However, a deeper analysis must be conducted on the $\left(\frac{C_{r, 1}}{C_{w, 2}}\right)$ ratio to determine the optimal number of regeneration cycles.

In order to find the optimal number of regeneration cycles $\left(n_{i}^{*}\right)$, the first derivative of $\left(\frac{C_{r, 1}}{C_{w, 2}}\right)$ in terms of $\sum_{0}^{n_{i}} x_{i}$ and $n_{i}{ }^{*}$ can be determined having $\frac{d\left(\frac{C_{r, 1}}{C_{w_{v, 2}}}\right)}{d\left(\sum_{0}^{n_{i}} x_{i}\right)}=0$.

The optimal number of regenerations $\left(n_{i}{ }^{*}\right)$ was numerically determined and presented in Table 3. Based on the found results comparing both strategies (with and without regeneration) in terms of the ratio $\left(\frac{C_{r, 1}}{C_{w, 2}}\right)$, at the beginning of the process (filling up the GAC filters with virgin material) both scenarios have to spend the same amount of money for purchasing the GAC, therefore $\left(\frac{C_{r, 1}}{C_{w, 2}}\right)=1$. However, after the first two years, in scenario two, all GAC-Exh is replaced and an investment of USD 6270 to buy fresh GACVirgin is required. Meanwhile, in scenario one, an investment of just USD 569.4 is needed for regenerating one ton of GAC-Exh. That means that in the first two years for scenario one, an investment of only USD $6270+569.4$ is required and for scenario two, this increases to USD $6270+6270$. However, due to regeneration, a small loss of GAC material could be possible. It will be proposed to do this regeneration in situ for future installation, which reduce this loss to a minimum. On the other side, an extra cost has to be included in the construction of the GAC filter as the actual GAC filters in the WTU are made from carbon steel. The use of $\mathrm{HCl}$ during regeneration demands special construction materials, e.g., stainless steel (see supplementary information).

Thus $\frac{C_{r, 1}}{C_{c_{w}, 2}}=\frac{6839.4}{12,540}=0.545$

$n_{i}^{*}$ : Optimal number of regenerations.

Following the dynamics of the $\left(\frac{C_{r, 1}}{C_{w, 2}}\right)$ economic function from Table 3, the economic profit increases with the number of regeneration cycles. However, a minimum value of $\left(\frac{C_{r, 1}}{C_{w, 2}}\right)$ is eventually found which in turn corresponds to a maximal economic profit. The optimal number of regenerations is found to be seven, which is also confirmed using the first derivative function. The mathematical optimal point occurs when the first derivative function equals zero between six and seven regeneration cycles. However, regeneration is 
in this case a discrete function and seven regeneration cycles can be considered as optimum number, as shown in Figure 5.

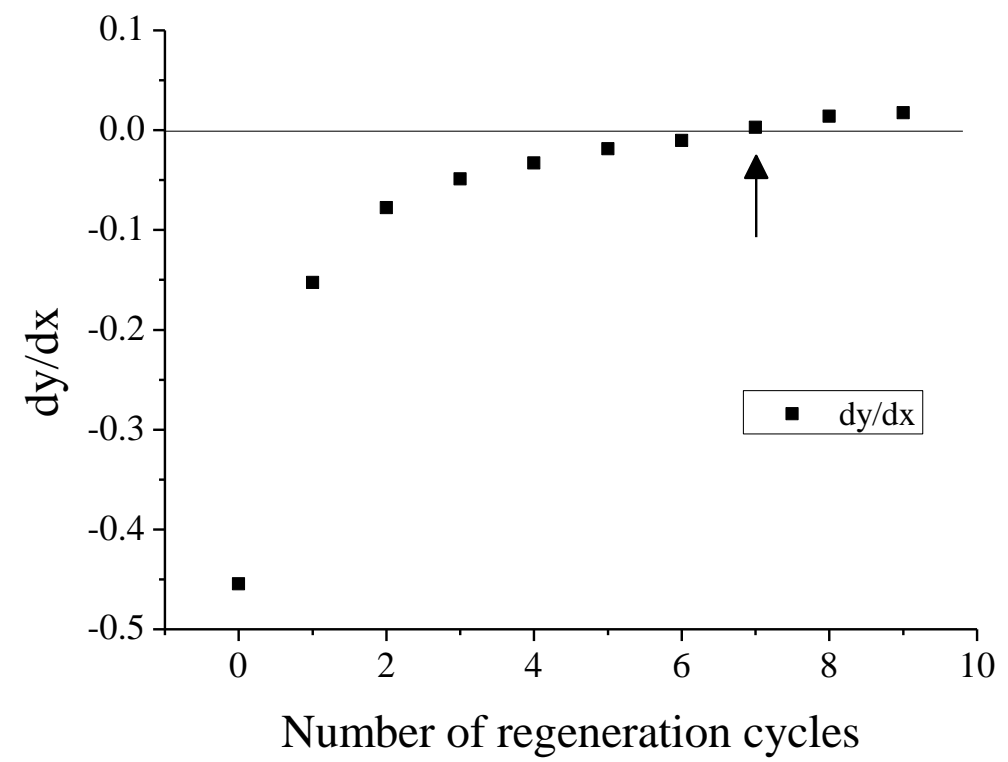

Figure 5. Optimal number of GAC regeneration cycles based on derivative function. $\frac{d y}{d x}=\frac{d\left(\frac{C_{r, 1}}{C_{w, 2}}\right)}{d\left(\sum_{0}^{n_{i}} x_{i}\right)}$.

For seven regeneration cycles, the saturation time represents about $33 \%$ of the saturation time of virgin material. According to the obtained results, the $\left(\frac{C_{r, 1}}{C_{w, 2}}\right)$ function starts to increase after seven cycles, thus indicating that the profitability of the regeneration process is going down due to the reduced saturation time of the regenerated GAC, which is confirmed by the sign switch $(-$ to + ) of the derivative function. As the regeneration cost is quite low compared with purchasing GAC-Virgin, the function $\left(\frac{C_{r, 1}}{C_{w, 2}}\right)$ is still under the critical value of one even after 10 regenerations. However, to keep the regeneration strategy over seven cycles, the saturation time of the regenerated GAC will drop to very low values (near to zero) and the frequency of regenerations to be performed will increase significantly $\left(n_{r \rightarrow \infty}\right)$ and according to Equation (28) also the function $\left(\frac{C_{r, 1}}{C_{w, 2}}\right)$. Therefore, an optimization analysis permits us to determine the optimal number of regenerations.

Figure 6 presents the plots of the economic index $\left(\frac{C_{r, 1}}{C_{w, 2}}\right)$ behaviour in function of the number of regeneration cycles (Table 3). The optimal economic profit is at $n_{i}{ }^{*}=7$. The economic index is the practical outcome of the deducted model to evaluate the GAC management strategy. It can be noticed that $0<\left(\frac{C_{r, 1}}{C_{w, 2}}\right)<1$, therefore the regeneration is economically favourable even for higher costs of chemical regeneration cycles. In regeneration cycle seven (about 11 years of exploitation), in scenario one, just about $26 \%$ of the cost is invested compared with scenario two, which had to purchase almost six tons of virgin GAC within this period of operation. After seven regenerations, in scenario one, all the GAC-Exh had to be replaced to restart the process. The reduced saturation time of the regenerated GAC beyond seven regenerations cycles is too short to prolong the regeneration strategy. These results demonstrate the advantages of regeneration in scenario one over scenario two, not only considering the economic but also the environmental criteria in order to reduce the amount of exhausted material landfilled by scenario 2 . However, during regeneration, a solution is generated after filtration, where the $\mathrm{HCl}$ is continuously reacting/consuming with the $\mathrm{CaCO}_{3}$ reducing the final $\mathrm{pH}$ of the solution. Finally, the solution mainly contains $\mathrm{CaCl}_{2}$, which can have other practical applications (see Supplementary Material Section S2). Therefore, the cost for treatment of the effluent solution from the filter can be limited since there will be profits. Additionally, this ap- 
proach (closing the circles) is advantageous for the environment and contributes to the sustainability of the regeneration process.

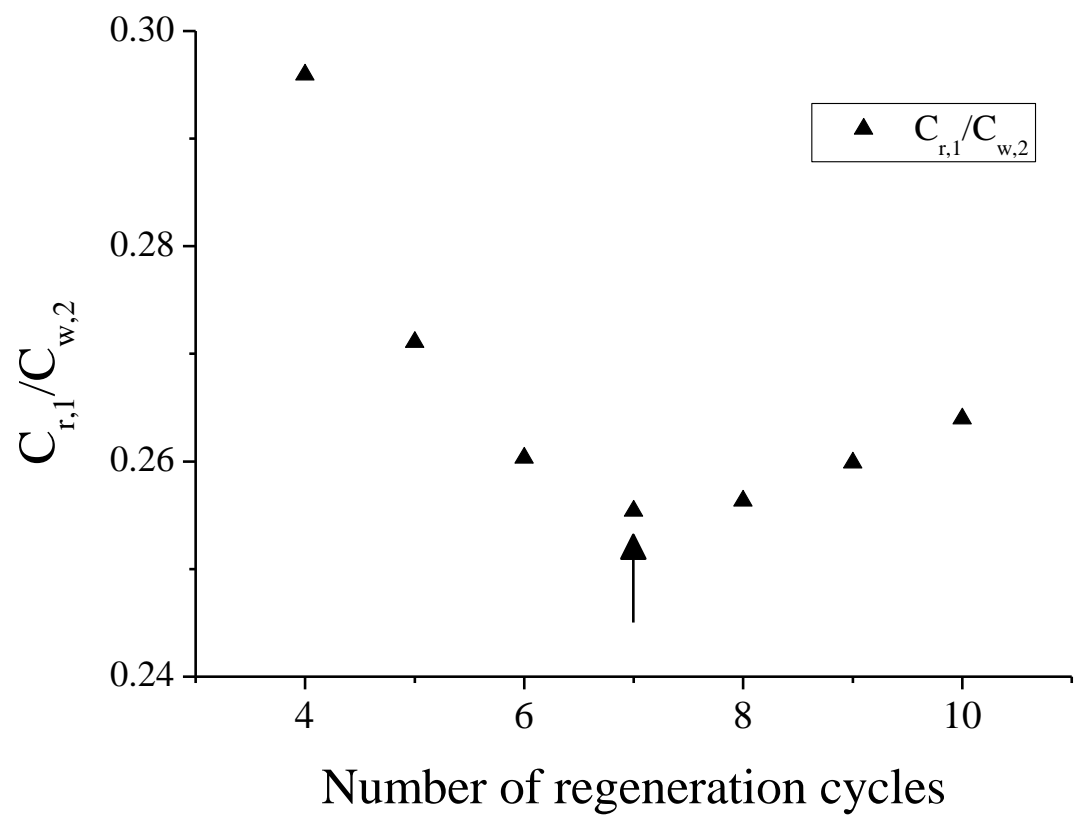

Figure 6. Optimal number of GAC regeneration cycles.

It is important to notice that the economic index $\left(\frac{C_{r, 1}}{C_{w, 2}}\right)$ was calculated considering $P_{\mathrm{HCl}}$ and $P_{v}$ as fixed values (no influence of the fluctuating GAC and $\mathrm{HCl}$ trade prices). However, other possible economic fluctuations in the GAC market or/and extra costs associated with industrial services, although not considered in this work in order to simplify the analysis, can be also included in the proposed mathematical tool of Equation (28). The presented economic tool can be applied in a flexible way under whatever fluctuations in economic and/or industrial variables.

The advantages of the proposed economic tool aimed to assess the GAC management strategy were demonstrated. However, economic and industrial changing scenarios could be more complex, depending on the economic conditions in the international market and used regeneration technology including GAC performance. Nevertheless, the implementation of the proposed economic index is flexible to study economic and/or process changes.

\subsection{General Considerations about Other Needed Investment for GAC Regeneration}

Although the economic advantages of GAC regeneration were demonstrated, additional investments have to be considered before applying the regeneration strategy. The actual GAC filter in the water treatment plant is made from carbon steel. Therefore, an initial investment in a new filter has to be included. The use of $\mathrm{HCl}$ during regeneration demands special construction materials (e.g., stainless steel SS304 or SS316). However, for the required dimension and material of the filter costs are limited and represent a fixed cost in the process. These extra considerations must be implemented in future studies in order to determine all the investment costs required and the internal rate of return (IRR) as a metric used in capital budgeting to estimate the return of potential investments.

\section{Conclusions}

This work reports an approach for the economic assessment of the GAC regeneration process based on an economic tool comparing two scenarios with different GAC management strategies as a study case. The tool can be applied jointly with regeneration performance equilibria data which can be obtained experimentally based on analysis of breakthrough saturation curves in saturation/regeneration cycles. 
Results indicated that under actual industrial and market conditions for the analysed scenarios, the chemical regeneration is profitable and should be applied in water treatment systems of power plants where the regeneration has not been considered yet. In addition, environmental and economic advantages are derived from the regeneration strategy which implies a significant reduction of about 6 tons of solid waste residue of exhausted GAC compared with a non-regenerating approach. The proposed tool permits the determination of the optimal number of regeneration cycles to maximize the economic profit during the implementation of the regeneration practice.

The presented economic index is a useful, efficient and fast-predicting tool to help specialists make decisions concerning the optimal profitability on the GAC management strategy to follow in order to face future changes in the economic and/or industrial scenarios. Additionally, this approach will also contribute to the sustainability of the water treatment process.

Supplementary Materials: The following are available online at http://www.mdpi.com/xxx/s1, Figure S1: General diagram of water treatment unit.

Author Contributions: Conceptualization, T.M.P.; Formal analysis, T.M.P.; Investigation, T.M.P., J.P.T. and L.S.G.; Methodology, T.M.P., H.C.S. and Á.S.R.; Project administration, H.C.S. and J.Y.; Resources, J.Y.; Supervision, H.C.S., J.Y., Á.S.R. and R.C.; Writing-original draft, T.M.P.; Writing-review \& editing, T.M.P., H.C.S., J.Y., Á.S.R. and R.C. All authors have read and agreed to the published version of the manuscript.

Funding: This research received no external funding.

Institutional Review Board Statement: Not applicable.

Informed Consent Statement: Not applicable.

Data Availability Statement: The study did not report any data.

Acknowledgments: The authors would like to thanks the VLIR-UOS project between Belgium and Cuba for providing funding and granting the support of the current and future studies.

Conflicts of Interest: The authors declare no conflict of interest.

\section{References}

1. Bansal, R.C.; Goyal, M. Activated Carbon Adsorption; Taylor \& Francis Group: Boca Raton, FL, USA, 2020.

2. Baker, F.S.; Miller, C.E.; Repik, A.J.; Tolles, E.D. Activated Carbon. In Kirk-Othmer Encyclopedia of Chemical Technology; John Wiley \& Sons, Inc.: Hoboken, NJ, USA, 2000; pp. 741-761.

3. Report, M.R. Activated Carbon Market Size, Share \& Trends Analysis Report by Product (Powdered, Granular), by Application (Liquid, Gas), by End Use (Water Treatment, Air Purification), by Region, and Segment Forecasts, 2019-2025. Mark. Res. 2019, 5785355. Available online: https://www.giiresearch.com/report/grvi361254-activated-carbon-market-analysis-by-product.html (accessed on 20 August 2021).

4. Dias, J.M.; Alvim-Ferraz, M.C.; Almeida, M.F.; Rivera-Utrilla, J.; Sanchez-Polo, M. Waste materials for activated carbon preparation and its use in aqueous-phase treatment: A review. J. Environ. Manag. 2007, 85, 833-846. [CrossRef]

5. Xu, G.; Zhang, L.; Yu, W.; Sun, Z.; Guan, J.; Zhang, J.; Lin, J.; Zhou, J.; Fan, J.; Murugadoss, V. Low optical dosage heating-reduced viscosity for fast and large-scale cleanup of spilled crude oil by reduced graphene oxide melamine nanocomposite adsorbents. Nanotechnology 2020, 31, 225402. [CrossRef] [PubMed]

6. Zhang, L.; Ma, P.; Dai, L.; Li, S.; Yu, W.; Guan, J. In situ crystallization and growth of $\mathrm{TiO}_{2}$ nanospheres between MXene layers for improved adsorption and visible light photocatalysis. Catal. Sci. Technol. 2021, 11, 3834-3844. [CrossRef]

7. Boruah, P.K.; Sharma, B.; Hussain, N.; Das, M.R. Magnetically recoverable $\mathrm{Fe}_{3} \mathrm{O}_{4}$ /graphene nanocomposite towards efficient removal of triazine pesticides from aqueous solution: Investigation of the adsorption phenomenon and specific ion effect. Chemosphere 2017, 168, 1058-1067. [CrossRef]

8. Fraga, T.J.M.; de Lima, L.E.M.; de Souza, Z.S.B.; Carvalho, M.N.; de Luna Freire, E.M.P.; da Motta, M.A. Amino-Fe ${ }_{3} \mathrm{O}_{4}{ }^{-}$ functionalized graphene oxide as a novel adsorbent of Methylene Blue: Kinetics, equilibrium, and recyclability aspects. Environ. Sci. Pollut. Res. 2019, 26, 28593-28602. [CrossRef] [PubMed]

9. Kim, S.; Gholamirad, F.; Yu, M.; Park, C.M.; Jang, A.; Jang, M.; Taheri-Qazvini, N.; Yoon, Y. Enhanced adsorption performance for selected pharmaceutical compounds by soni-cated $\mathrm{Ti}_{3} \mathrm{C}_{2} \mathrm{TX}$ MXene. Chem. Eng. J. 2021, 406, 126789. [CrossRef]

10. Zhu, J.; Ha, E.; Zhao, G.; Zhou, Y.; Huang, D.; Yue, G.; Hu, L.; Sun, N.; Wang, Y.; Lee, L.Y.S. Recent advance in MXenes: A promising 2D material for catalysis, sensor and chemical adsorption. Coord. Chem. Rev. 2017, 352, 306-327. [CrossRef] 
11. Jun, B.-M.; Kim, S.; Rho, H.; Park, C.M.; Yoon, Y. Ultrasound-assisted $\mathrm{Ti}_{3} \mathrm{C}_{2} \mathrm{Tx}$ MXene adsorption of dyes: Removal performance and mechanism analyses via dynamic light scattering. Chemosphere 2020, 254, 126827. [CrossRef]

12. Kong, D.; Gao, Y.; Xiao, Z.; Xu, X.; Li, X.; Zhi, L. Rational Design of Carbon-Rich Materials for Energy Storage and Conversion. Adv. Mater. 2019, 31, e1804973. [CrossRef] [PubMed]

13. Fa, S.; Yamamoto, M.; Nishihara, H.; Sakamoto, R.; Kamiya, K.; Nishina, Y.; Ogoshi, T. Carbon-rich materials with threedimensional ordering at the angstrom level. Chem. Sci. 2020, 11, 5866-5873. [CrossRef]

14. Radovic, L.R. Chemistry E Physics of Carbon; CRC Press: Boca Raton, FL, USA, 2004; Volume 30.

15. Shah, I.K.; Pre, P.; Alappat, B.J. Steam regeneration of adsorbents: An experimental and technical review. Chem. Sci. Trans. 2013, 2, 1078-1088.

16. Chowdhury, Z.K. Activated Carbon: Solutions for Improving Water Quality; American Water Works Association: Denver, CO, USA, 2013.

17. Çeçen, F.; Aktas, Ö. Activated Carbon for Water and Wastewater Treatment: Integration of Ad-Sorption and Biological Treatment; John Wiley \& Sons: Istambul, Turkey, 2011.

18. McCabe, W.L.; Smith, J.C.; Harriott, P. Unit Operations of Chemical Engineering, 6th ed.; McGraw-Hill: Singapore, 2001; Volume 15, pp. 821-834.

19. Miguel, G.S.; Lambert, S.; Graham, N. The regeneration of field-spent granular-activated carbons. Water Res. 2001, 35, 2740-2748. [CrossRef]

20. He, K. A calculation of the environmental footprint of a granular activated carbon regeneration facility. Climate and Energy section; Environmental Sciences Senior Thesis Symposium. UC Berkeley Environ. Sci. 2012, 22, 1-23.

21. Toyoko, I. Activated carbon surfaces in environmental remediation. In Advanced Chemistry of Monolayers at Interfaces: Trends in Methodology and Technology; Elsevier Ltd.: Oxford, UK, 2007; Volume 7.

22. Fernández, M.C.; Fernández, M.F.; Fuentes, R.D.; Montiel, Á.C. Energy quality and Distributed Generation in Cuba. Cuba. J. Eng. 2011, 1, 41-50.

23. Anders, G.J.; Vaccaro, A. Innovations in Power Systems Reliability; Springer: London, UK, 2011.

24. Čepin, M. Assessment of Power System Reliability: Methods and Applications; Springer Science \& Business Media: London, UK, 2011.

25. Llanes-Cedeño, E.A.; Guardia-Puebla, Y.; de la Rosa-Andino, A.; Cevallos-Carvajal, S.; Rocha-Hoyos, J.C. Detection of Faults in Combustion Engines Through Indicators of Temperature and Injection Pressure. Ingenius J. Sci. Technol. 2019, $22,38-46$.

26. Guo, Y.; Du, E. The Effects of Thermal Regeneration Conditions and Inorganic Compounds on the Characteristics of Activated Carbon Used in Power Plant. Energy Procedia 2012, 17, 444-449. [CrossRef]

27. Habbart, L. Treatment of Cooling Water; Springer Science \& Business Media: Berlin/Heidelberg, Germany, 2009 ; pp. 7-10.

28. Amjad, Z. The Science and Technology of Industrial Water Treatment; CRC Press: Boca Raton, FL, USA, 2010.

29. Salvador, F.; Martin-Sanchez, N.; Sánchez-Hernández, R.; Sanchez-Montero, M.J.; Izquierdo, C. Regeneration of carbonaceous adsorbents. Part II: Chemical, Microbiological and Vacuum Regeneration. Microporous Mesoporous Mater. 2015, 202, 277-296. [CrossRef]

30. El Gamal, M.; Mousa, H.A.; El-Naas, M.H.; Zacharia, R.; Judd, S. Bio-regeneration of activated carbon: A comprehensive review. Sep. Purif. Technol. 2018, 197, 345-359. [CrossRef]

31. Martin, R.; Ng, W. Chemical regeneration of exhausted activated carbon-I. Water Res. 1984, 18, 59-73. [CrossRef]

32. Lambert, S.D.; Miguel, G.S.; Graham, N.J. Deleterious effects of inorganic compounds during thermal regeneration of GAC: A Review. J. Am. Water Work. Assoc. 2002, 94, 109-119. [CrossRef]

33. Bottani, E.J.; Tascón, J.M. Adsorption by Carbons; Elsevier Ltd.: Amsterdam, The Netherlands, 2008.

34. Serp, P.; Figueiredo, J.L. Carbon Materials for Catalysis; John Wiley \& Sons: Hoboken, NJ, USA, 2009.

35. Mazyck, D.W.; Cannon, F.S. Overcoming calcium catalysis during the thermal reactivation of granular activated carbon: Part I. Steam-curing plus ramped-temperature $\mathrm{N}_{2}$ treatment. Carbon 2000, 38, 1785-1799. [CrossRef]

36. Perry, L.; Essex, D.; Giess, P.; Graham, N.; Kaur, K.; Lambert, S.; Spencer, C. Improving the performance of granular activated carbon (GAC) via pre-regeneration acid treatment. Water Environ. J. 2005, 19, 159-166. [CrossRef]

37. Worch, E. Adsorption Technology in Water Treatment: Fundamentals, Processes, and Modeling; Walter de Gruyter GmbH \& Co: Göttingen, Germany, 2012; pp. 25-268. ISBN 978-3-11-024022-1.

38. Zeng, C.; Atkinson, A.; Sharma, N.; Ashani, H.; Hjelmstad, A.; Venkatesh, K.; Westerhoff, P. Removing per- and polyfluoroalkyl substances from groundwaters using activated carbon and ion exchange resin packed columns. AWWA Water Sci. $2020,2,1172$. [CrossRef]

39. Zietzschmann, F.; Müller, J.; Sperlich, A.; Ruhl, A.S.; Meinel, F.; Altmann, J.; Jekel, M. Rapid small-scale column testing of granular activated carbon for organic micro-pollutant removal in treated domestic wastewater. Water Sci. Technol. 2014, 70, 1271-1278. [CrossRef]

40. Mariño Peacok, T.; Crespo Sariol, H.; Yperman, J.; Sánchez Roca, Á; Carleer, R.; Puente Torres, J.; Reggers, G.; Haeldermans, T.; Thijssen, E.; Samyn, P. Improvement of a new acoustic emission analysis technique to determine the activated carbon saturation level: A comparative study. J. Environ. Chem. Eng. 2020, 8, 103794. [CrossRef]

41. Mariño Peacok, T.; Crespo Sariol, H.; Sánchez Roca, Á; Puente Torres, J.; Gryglewicz, G.; Yperman, J.; Carleer, R.; Vandamme, D.; Reggers, G.; Vanreppelen, K. Efficiency evaluation of thermally and chemically regenerated activated carbons used in a water cleaning system by acoustic emission analysis. J. Porous Mater. 2021, 28, 451-469. [CrossRef] 
42. US Environmental Protection Agency Office of Pesticide Programs. Standard Operating Procedure for Preparation of Hard Water and Other Diluents for Antimicrobial Products; Office of Pesticide Programs Microbiology Laboratory Environmental Science Center Ft. Meade: Irvine, CA, USA, 2019.

43. Kaiser, C.J. The Use of Small-Scale Equipment for Evaluating Water Treatment Plants; Water Research Commission: Natal, South Africa, 1999.

44. Martín-Lara, M.Á.; Miranda, M.C.T.; Gálvez, A.R.; Muñoz, A.P.; de Hoces, M.C. Valorization of olive stone as adsorbent of chromium (VI): Comparison between laboratory- and pilot-scale fixed-bed columns. Int. J. Environ. Sci. Technol. 2017, 14, 2661-2674. [CrossRef]

45. Ronda, A.; Martín-Lara, M.; Osegueda, O.; Castillo, V.; Blázquez, G. Scale-up of a packed bed column for wastewater treatment. Water Sci. Technol. 2018, 77, 1386-1396. [CrossRef]

46. Calero, M.; Ronda, A.; Pérez, A.; Yáñez, A.; Trujillo, M.C.; Martín-Lara, M.Á. The scale-up of $\mathrm{Cr}^{3+}$ biosorption onto olive stone in a fixed bed column. Desalination Water Treat. 2016, 57, 25140-25152. [CrossRef]

47. ASTM. D2854-09: Standard Test Methods for Apparent Density of Activated Carbon; American Society for Testing and Materials: West Conshohocken, PA, USA, 2019.

48. Liu, J.; Yan, Y.; Zhang, H. Adsorption dynamics of toluene in composite bed with microfibrous entrapped activated carbon. Chem. Eng. J. 2011, 173, 456-462. [CrossRef]

49. Power Plants, S.L. Economic and Costs Data Records. Unpublished work, 2019.

50. Genç, N.; Durna, E.; Erkişi, E. Optimization of the adsorption of diclofenac by activated carbon and the acidic regeneration of spent activated carbon. Water Sci. Technol. 2021, 83, 396-408. [CrossRef]

51. Nunes, K.G.P.; Sfreddo, L.W.; Rosset, M.; Féris, L.A. Efficiency evaluation of thermal, ultrasound and solvent techniques in activated carbon regeneration. Environ. Technol. 2020, 42, 4189-4200. [CrossRef]

52. Siriwardena, D.P.; James, R.; Dasu, K.; Thorn, J.; Iery, R.D.; Pala, F.; Schumitz, D.; Eastwood, S.; Burkitt, N. Regeneration of per- and polyfluoroalkyl substance-laden granular activated carbon using a solvent based technology. J. Environ. Manag. 2021, 289, 112439. [CrossRef] [PubMed]

53. Spessato, L.; Bedin, K.C.; Cazetta, A.L.; de Souza, L.S.; Duarte, V.A.; Crespo, L.H.; Silva, M.C.; Pontes, R.M.; Almeida, V.C. $\mathrm{KOH}$-super activated carbon from biomass waste: Insights into the paracetamol adsorption mechanism and thermal regeneration cycles. J. Hazard. Mater. 2019, 371, 499-505. [CrossRef] [PubMed]

54. Sun, Y.; Zhang, B.; Zheng, T.; Wang, P. Regeneration of activated carbon saturated with chloramphenicol by microwave and ultraviolet irradiation. Chem. Eng. J. 2017, 320, 264-270. [CrossRef] 